\title{
Endless Arguments Over Diversion Stomas
}

\author{
Seung Chul Heo \\ Department of Surgery, SMG-SNU Boramae Medical Center, Seoul, Korea
}

See Article on Page 118-121

Diversion stoma is an anastomosis protection method frequently used in colorectal surgery. Recent increase of sphincter-preserving surgery, preoperative radiation therapy and laparoscopic surgery has the demand for a diversion ileostomy rising. Accordingly, three have been consistent and diverse arguments about the advantages and the disadvantages of the various methods in creating and restoring the diversion stoma.

The typical issues are the pros and the cons for an ileostomy and a colostomy. Evidence is not sufficient to determine which is superior, an ileostomy or a colostomy [1]. Although dehydration and renal failure are concerns with an ileostomy $[2,3]$, it has become the preferred procedure because of its several advantages: (1) Formation of stoma in the midline of the abdomen is not necessary; (2) Adhesion with the greater omentum is less common than transverse colostomy; (3) Ileostomy is usually safe and anatomically convenient after rectosigmoid colon surgery in which diversion stoma is most commonly needed.

In addition, purse-string suture (PSS) as a technique for skin closure has been reported to reduce surgical site infection (SSI) when doing an ileostomy take down [4]. However, whether the anatomical closure of the abdominal wall was performed accurately must be considered if they would compare skin closure methods. In my personal experience, SSI is not a significant problem and the stitches can usually be removed after 1 week, in case of the ileostomy formed within the rectus abdominis muscle, if the peritoneum grown up within the rectus muscle is removed and if the anterior and posterior fascia are closed separately making the naked rectus muscle belly rejoined. Therefore, more evidence is nec-

Correspondence to: Seung Chul Heo, M.D.

Department of Surgery, SMG-SNU Boramae Medical Center, Seoul National University College of Medicine, 20 Boramae-ro 5-gil, Dongjak-gu,

Seoul 156-707, Korea

Tel: +82-2-870-2273, Fax: +82-2-870-3866

E-mail: heosc3@brm.co.kr

(C) 2014 The Korean Society of Coloproctology

This is an open-access article distributed under the terms of the Creative Commons Attribution NonCommercial License (http://creativecommons.org/licenses/by-nc/3.0) which permits unrestricted noncommercial use, distribution, and reproduction in any medium, provided the original work is properly cited. essary through further research whether PSS which is cosmetically superior but requires laborious dressing during the discharge of 2-3 weeks is worthwhile to replace the primary closure.

Cheong et al. [5] mentioned that there were no differences between the fold-over technique and the resection anastomosis technique of ileostomy take down. The fold-over technique can be simpler and be more useful when the distal loop is short. However, it can increase the risk of contamination by bowel content, and the procedure may not be possible when the distal loop has been made narrow to prevent spill over.

Many investigators have identified that a randomized, largescale study is needed in order to reach a firm conclusion, but each surgical procedure has advantages and disadvantages. And controlling all of the factors in a randomized study will not be easy. Therefore, a realistic alternative would be to choose an appropriate method depending on the situation by knowing the arguments and by understanding the advantages and the disadvantages of each procedure in creating and restoring diversion stoma.

\section{REFERENCES}

1. Chen J, Wang DR, Zhang JR, Li P, Niu G, Lu Q. Meta-analysis of temporary ileostomy versus colostomy for colorectal anastomoses. Acta Chir Belg 2013;113:330-9.

2. Jafari MD, Halabi WJ, Jafari F, Nguyen VQ, Stamos MJ, Carmichael JC, et al. Morbidity of diverting ileostomy for rectal cancer: analysis of the American College of Surgeons National Surgical Quality Improvement Program. Am Surg 2013;79:1034-9.

3. Paquette IM, Solan P, Rafferty JF, Ferguson MA, Davis BR. Readmission for dehydration or renal failure after ileostomy creation. Dis Colon Rectum 2013;56:974-9.

4. Dusch N, Goranova D, Herrle F, Niedergethmann M, Kienle P. Randomized controlled trial: comparison of two surgical techniques for closing the wound following ileostomy closure: purse string vs direct suture. Colorectal Dis 2013;15:1033-40.

5. Cheong J, Kang J, Kim IK, Kim NK, Sohn SK, Lee KY. Feasibility and safety of a fold-over diverting ileostomy reversal after rectal cancer surgery: case-matched comparison to the resection technique. Ann Coloproctol 2014;30:118-21. 